\title{
Effect of adaptive movement on durability and working time of twisted file
}

\author{
Sang-Ho Lee, So-Ra Park, Kyung-Mo Cho, Se-Hee Park, Jin-Woo Kim* \\ Department of Conservative Dentistry, College of Dentistry, Gangneung-Wonju National University School of Dentistry, \\ Gangneung, Republic of Korea
}

Purpose: Recently TF-adaptive movement is developed in order to increase the durability of TF files. The purpose of this study was to assess the effects of adaptive movement on durability and performance of twisted files. Materials and Methods: Resin blocks simulating artificial J-shape canals were used for this study. In TFC group, TF-adaptive ML-1 (25/.08 size) files were used to prepare the canals under continuous rotation $500 \mathrm{rpm} / 4.0 \mathrm{Ncm}$. In TFA group, TF-adaptive ML-1 (25/.08 size) files were used to prepare the canals under adaptive movement. After preparing each artificial canal, TF files were observed under dental microscope for assessing existence of unwinding, distortion, and fracture. If unwinding of flute was observed, the number of artificial canals until unwinding of flute occurs was recorded. Required time until instruments reach working length and distance of unwinded portion of files from D0 were measured. All test results were conducted by Mann-Whitney U test at a 0.05 level of significance. Results: No NiTi instrument's separation was observed. Number of resin blocks until file unwinding happens and working time was significantly high in TFA group compared to TF group. Distance of distortion from D0 didn't show significant difference between TFA, TF groups. Conclusion: The number of resin blocks prepared until unwinding happens and working time were significantly high in TFA group. The location of unwinding showed no significant difference between 2 groups. Adaptive movement increased the number of canals prepared until unwinding occurs and working time of twisted files. (J Dent Rehabil Appl Sci 2019;35(1):20-6)

Key words: NiTi file; twisted file; adaptive movement; unwinding

\section{서론}

근관치료는 치근관 내부의 감염된 상아질과 치수 잔사 등 잠재적인 감염원을 제거하고 근관벽을 연속적인 형태 로 형성하는 과정을 포함하며, 이 과정에서 임상가는 복 잡한 치근과 치근관의 해부학적 형태로 인해 종종 어려 움을 겪는다. 니켈 티타늄 합금을 이용한 근관치료용 절 삭 기구가 도입되면서 근관치료학은 큰 발전의 기회를 맞았는데, 형상 기억 합금인 니켈 티타늄 합금은 기존의 근관 절삭 기구의 재료였던 스테인리스 스틸에 비해 유 연성이 뛰어나, 복잡한 치근관의 형태를 따라 근관의 확 대 및 형성이 가능하게 되었다. ${ }^{1}$ 하지만 니켈 티타늄 합금

*Correspondence to: Jin-Woo Kim

Professor, Department of Conservative Dentistry, College of Dentistry, Gangneung-Wonju National University, 7, Jukheon-gil, Gangneung, 25457, Republic of Korea

Tel: +82-33-640-3189, Fax: +82-33-640-3103, E-mail: mendo7@gwnu.ac.kr Received: November 12, 2018/Last Revision: February 25, 2019/Accepted: March 3, 2019
은 스테인리스 스틸에 비해 내구성이 낮다는 단점이 존 재하여 파일이 파절 및 변형되는 부작용이 더 빈번하게 발생하게 되었다. 이러한 부작용을 줄이기 위하여 다양 한 시도가 이루어졌고, 파일을 기계로 절삭하여 만드는 방식이 아닌, 금속을 꼬아서 만드는 방식의 파일(twisted file, TF)이 소개되었는데, ${ }^{2}$ 일반적인 절삭 가공을 통한 방 식으로 제작하지 않았기 때문에 파일의 균열발생에 기여 할 수 있는 파일 표면의 기계적 결함(예: 절삭선 등)이 더 적게 관찰되었다. ${ }^{3,4}$ 또한, twisted file은 기존 방식으로 제 조된 NiTi 파일에 비하여 유연성이 높고, 이는 피로 파절 에 대한 저항 증가로 이어졌다. ${ }^{3,5-8}$ 하지만, 금속을 꼬아 서 가공하는 방식 특유의 한계로 인해 근관 내에서 회전

CopyrightC 2019 The Korean Academy of Stomatognathic Function and Occlusion. (c) It is identical to Creative Commons Non-Commercial License. 
하는 중에 torsional stress 를 받을 시에 파일의 날이 풀 리는(unwinding) 현상이 발생하였다. ${ }^{9,10}$ 이로 인해 파일 은 기존의 pitch 길이 등 기계적인 특성이 변화하게 되고, ${ }^{2}$ 그 결과로 파일의 물리적 성상이 처음의 상태와는 달라 져, 임상에서 변수로 작용할 수 있었다.

$\mathrm{TF}$ 의 이러한 단점을 극복하기 위하여, torsional stress 를 받기 전에는 $600^{\circ}$ 로 시계방향으로 회전한 뒤, $0^{\circ}$ 로 역 회전하고, 만약 torsional stress 가 가해질 시에는 구동엔 진이 상황을 인지하고 시계방향으로 $370^{\circ}$, 반시계방향으 로 $50^{\circ}$ 로 회전하는 reciprocating movement로 전환하는 adaptive movement가 개발되어 소개되었다. ${ }^{11}$ 이로 인 해 만약 파일이 그 기계적 특성을 잃어버리는 것을 방지 할 수 있다면, 형태의 변형 및 파일의 파절이 이루어지기 전까지 확대할 수 있는 근관의 수가 증가하지만, 파일의 한계점에서 과도한 회전을 제한함에 따라 파일의 삭제력 자체는 줄어들 것이다.

이에 본 연구에서는 다음과 같은 세 가지의 귀무가설 을 설정하여 이러한 adaptive movement가 twisted file 의 performance에 미치는 영향을 조사하고자 하였다. 첫 째, twisted file을 adaptive mode로 사용할 경우 기존의 continuous rotary movement로 사용할 때에 비하여 파일 의 날 풀림이 차이가 없을 것이다. 두번째, twisted file을 adaptive mode와 기존의 continuous rotary movement로 사용 시에 작업장까지 확대하는 시간의 차이가 없을 것이 다. 세번째, twisted file을 adaptive mode로 사용하더라도 기존의 continuous rotary movement에 비하여 기구의 날 풀림이 발생하는 위치 변화가 없을 것이다.

\section{연구 재료 및 방법}

\section{실험군}

본 연구에서는 두 개의 실험군을 사용하였다. 첫번째 실험군은 TF-adaptive file ML-1 (25/0.08 size, SybronEndo, Orange, USA)을 adaptive movement로 사용하 고(TFA군), 두번째 실험군은 TF-adaptive file ML-1을 $500 \mathrm{rpm}, 4.00 \mathrm{Ncm}$ 으로 continuous rotary movement 로 사용하여 근관을 확대하였다(TFC군). 각 군의 파일 은 15 개씩 사용하였다 $(\mathrm{n}=15)$. TF는 adaptive movement와 continuous rotary movement 모두 TF adaptive motor (SybronEndo)에 연결하여 사용하여 레진 모형 근 관을 형성하였다. 모든 TF 파일은 실험 전에 수술용 현미
경(M320, Leica Microsystems, Wetzlar, Germany) 하에 서 관찰하여 표면의 결손부 또는 날이 풀린 지점의 존재 여부 등을 확인하여 이상이 없는 파일만 사용하였다.

\section{레진 모형 근관}

ISO \#15, 0.02 taper의 J 형 레진 모형 근관(Dentsply Tulsa Dental, Tulsa, USA)을 사용하였으며, 모형 근관은 $30^{\circ}$ 의 만곡도를 가지며, ${ }^{12}$ 근관장은 $14.5 \mathrm{~mm}$ 이었다.

\section{모형 근관 형성}

선정된 레진 모형 근관의 coronal 부위를 ProTaper Universal SX file (Dentsply Tulsa Dental)을 이용하 여 coronal 부분을 preflaring 후, Pathfile 013, 016, 019 로 근관장까지 근관을 확대, 형성하여 glide path를 형성 하였다(Fig. 1). 이후 TFC군은 TF-adaptive file ML1을 continuous rotary movement로, TFA군은 TF adaptive file ML1을 adaptive movement로 사용하여 근관장까지 근관을 형성하였다. 근관세정제는 증류수를 사용하였으 며, 모든 기구 조작은 근관치료가 숙련된 한 명의 실험자 가 시행했다.

\section{현미경 분석}

근관 형성을 시작하기 전과 근관장 만큼 근관을 형성 한 이후에, 치과용 현미경을 이용하여 NiTi 파일의 날풀 림 등의 변형 또는 파절 등의 변화가 있는지 관찰하였다.

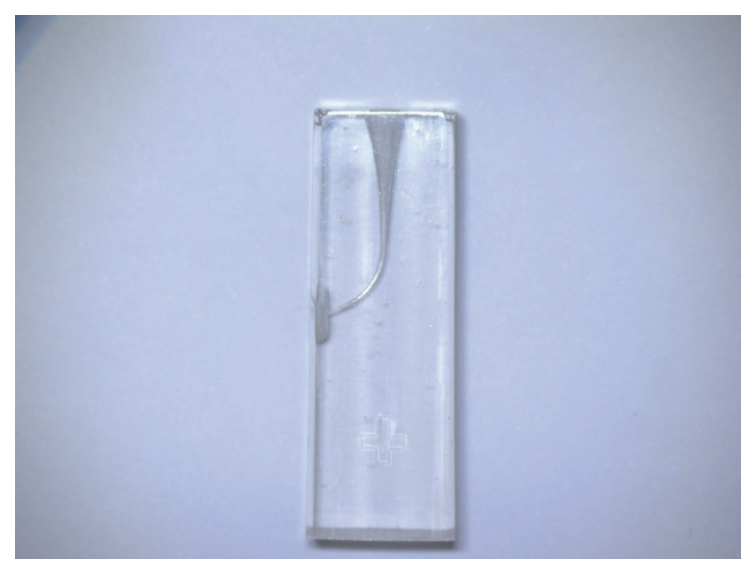

Fig. 1. Artificial canal completed with coronal preflaring and glide path preparation. 
한 개의 레진 모형 근관을 형성할 때마다 관찰하여 날풀 림 등의 변화가 발견될 시에는 그 파일을 이용하여 추가 로 근관을 형성하지 않고, 형성한 레진 모형 근관의 수를 기록하고, 기구의 사진을 촬영했다. 각 파일별로 날풀림 이 발견되기 전까지 형성한 레진 모형 근관의 수를 평균 계산했다.

\section{작업 시간 측정}

Coronal preflaring과 glide path 형성을 마친 이후에, $\mathrm{TFA}$ 군 및 $\mathrm{TF}$ 군에서 기구가 근관장까지 근관을 형성하 는데 소요된 시간을 측정했다. 근관 확장 도중 근관을 세 정하는 동안에는 시간을 측정하지 않았으며, 기구가 근 관장까지 형성한 즉시 시간 측정을 멈추었다. 각 레진 모 형 근관마다 측정된 시간의 평균을 계산하였다.

\section{날풀림 발생 위치 측정}

현미경 하에서 기구의 첨단(D0)에서 날풀림이 발생한 부위의 중앙부까지의 직선 거리를 디지털 캘리퍼를 이용 하여 측정하였다.

\section{통계 분석}

각 실험재료별로 측정된 레진 모형 근관의 평균 수와 작업장까지 도달하는데 소요된 평균 시간 및 두 집단에 서 날풀림이 발생한 위치의 D0 부터의 거리는 IBM SPSS software (IBM SPSS Inc, Chicago, USA)를 이용하여 $95 \%$ 의 유의수준에서 Mann-Whitney U test로 비모수 검 정하였다.

\section{결과}

$\mathrm{NiTi}$ 파일의 날풀림이 발생할 때까지 형성한 레진 모 형 근관의 수를 비교 시에 TFC 군이 TFA군에 비하여 유 의하게 적었다 $(P<0.05$, Table 1$)$. 모든 파일에서 기구 의 파절은 발생하지 않았다. $\mathrm{NiTi}$ 파일이 근관장까지 도 달하는데 소요된 시간은 TFA 군에서 TFC군에 비해 유 의하게 길었다 $(P<0.05)$ (Table 2). 기구의 첨단으로부터 날풀림이 발생한 위치까지의 수직 거리는 TFA군과 TFC 군 간에 유의한 차이가 없었다 $(P>0.05$, Table 3 , Fig. 2).
Table 1. Artificial canals prepared until unwinding of TF observed

\begin{tabular}{ccccc}
\hline Group & $\mathrm{n}$ & $\begin{array}{c}\text { mean } \\
\text { (No.) }\end{array}$ & $\begin{array}{c}\text { Standard } \\
\text { deviation }\end{array}$ & $P$ \\
\hline TFA & 15 & 5.07 & 1.22 & $<0.001$ \\
TFC & 15 & 1.53 & 0.74 & \\
\hline
\end{tabular}

TFA: Twisted file with adaptive movement, TFC: Twisted file with continuous movement.

Table 2. Working time required until TF reach full working length

\begin{tabular}{ccccc}
\hline Group & $\mathrm{n}$ & $\begin{array}{c}\text { mean } \\
(\mathrm{s})\end{array}$ & $\begin{array}{c}\text { Standard } \\
\text { deviation }\end{array}$ & $P$ \\
\hline TFA & 15 & 21.17 & 2.44 & $<0.001$ \\
TFC & 15 & 16.85 & 1.63 & \\
\hline
\end{tabular}

TFA: Twisted file with adaptive movement, TFC: Twisted file with continuous movement.

Table 3. Distance of D0 location of instruments' unwinding portion

\begin{tabular}{ccccc}
\hline Group & $\mathrm{n}$ & $\begin{array}{c}\text { mean } \\
(\mathrm{cm})\end{array}$ & $\begin{array}{c}\text { Standard } \\
\text { deviation }\end{array}$ & $P$ \\
\hline TFA & 15 & 4.19 & 1.29 & 0.067 \\
TFC & 15 & 3.41 & 1.08 & \\
\hline
\end{tabular}

TFA: Twisted file with adaptive movement, TFC: Twisted file with continuous movement.

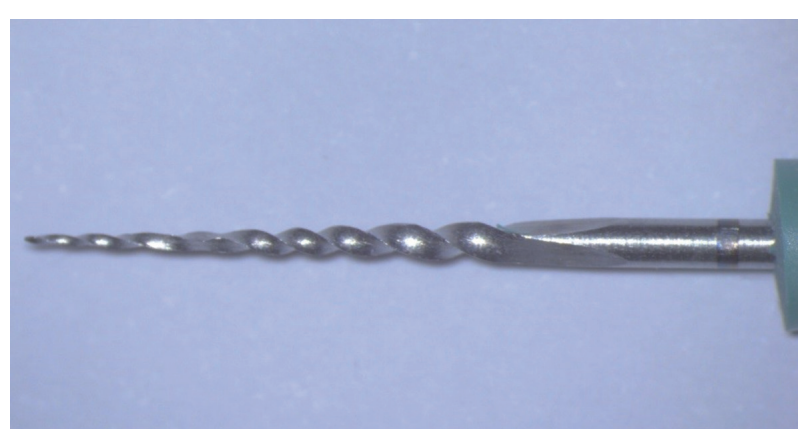

Fig. 2. TF instrument showing unwinding.

\section{총괄 및 고안}

$\mathrm{NiTi}$ 파일은 기존의 스테인리스 스틸 파일보다 우수 한 임상적 결과가 보고되면서, 기존의 파일을 대체하여 임상에서 널리 사용되고 있다. 그러나, NiTi 파일의 파절 에 대한 취약성이 대두되었고, 그 취약성을 보완하기 위 
한 다양한 시도가 이루어졌다. ${ }^{4,7,13}$ 그 중 하나로, $\mathrm{NiTi}$ 파일의 파절에 기여할 수 있는 machine groove 및 기구 의 미세 균열을 감소시켜, cyclic fatigue에 대한 저항성 을 증가시키기 위한 시도가 이루어졌다. ${ }^{3,8}$ 이러한 시도 중 하나로는, 기존의 방식대로 금속을 절삭하여 제조하 지 않고, wire를 꼬아서 제조하는 것으로, 이러한 방식으 로 제조된 기구는 절삭 가공된 파일에 비하여 machine groove 가 더 적게 존재하는 것이 보고되었다. ${ }^{3,14} \mathrm{Kim}$ 등 ${ }^{3}$ 은 절삭해서 제조한 ProTaper 파일과 $\mathrm{TF}$ 의 파절 저항성 을 비교하여, TF의 경우 분리된 파일의 crack이 machine groove 상에 존재하지 않으나, 절삭 가공한 Protaper Universal 파일의 경우 crack이 machine groove 상에 존 재하며, 이로 인해, machine groove가 많은 파일의 경 우 기구의 피로에 대해 더 높은 위험성을 가진다고 보고 하였다. 이러한 이유로 여러 연구에서 TF에서 기구의 유 연성 및 cyclic fatigue에 대한 저항성의 증가가 보고되었 다. ${ }^{3,5-8}$ 그러나, $\mathrm{TF}$ 의 경우 절삭식으로 제조한 파일에 비 하여 torsional fatigue에 대한 취약성 및 그로 인한 날풀 림 등의 변형이 보고되었다., ${ }^{9,10}$

이전 연구에서, NiTi 파일의 수명을 연장시키기 위한 시도 중 하나로, 파일이 근관 내에서 한 방향으로 지속적 으로 회전하는 것이 아닌, 반대 방향으로 회전하는 과정 을 포함하는 reciprocating movement가 소개되었고 그 로 인해 $\mathrm{NiTi}$ 파일의 수명이 증가한 것이 보고되었다. ${ }^{11}$ 이에 따라, TF 역시도, 날풀림 등의 기구의 변형을 감소 시키기 위하여 파일이 근관 내에서 부하가 가해질 때에 지속적으로 회전하지 않고 반시계 방향으로 회전하여 기구에 가해지는 부하를 줄여주는 adaptive movement 가 개발되었다. ${ }^{11}$ 이번 실험의 결과에서 기존 continuous rotary 방식으로는 하나의 $\mathrm{TF}$ 기구로 1.53 개의 근관을 형성하여 이론적으로는 다근치에서 하나의 기구로 사용 할 수 없던 반면, adaptive movement로 사용 시에는 기 구에 누적되는 피로를 줄여서 기구의 변형이 발생하기 전 까지 형성한 평균 근관 수가 5.07개까지 증가하여 기구의 수명이 통계적으로 유의하게 증가하였다. 이번 연구에서 는 하나의 근관을 완전히 형성한 다음에 현미경으로 날 풀림 여부를 관찰하였다. 따라서, 하나의 근관을 완전히 형성하기 전에 날풀림이 발생했을 가능성이 있으며, 그러 한 상황에서도 근관을 완전히 형성한 다음 관찰하여 형 성한 레진 모형 근관 수를 측정했기 때문에 날이 풀리기 전까지 형성한 근관 수가 하나가 더 추가되어 측정되었 을 가능성이 존재한다. 실제로, 이번 실험에서 TFC군에
서는 형성한 근관의 수가 최소 1 개로 측정되었으나, 하나 의 근관을 형성하기 이전에 날풀림이 발생하였을 수 있 으며, TFA군에서는 최소 3 개 이상의 근관을 형성한 것으 로 측정되어, 실제로는 날풀림이 발생하기 전 형성 가능 한 근관의 수의 차이가 더욱 클 가능성이 존재한다. TFadaptive의 날풀림을 관찰한 이전의 연구에서, 수동기구 로 \#15까지 확대한 이후에 TF-adaptive SM-1, 2, 3 파일 을 사용하고 날풀림을 조사한 결과 8 - 10 개의 근관을 형 성한 이후에는 전체 기구의 $96 \%$ 에서 날풀림이 발생하였 다. ${ }^{9}$ 이번 연구에서 조사된 TFA군의 평균 형성 근관 수인 5.07 개와 결과값의 차이를 보이는 이유는 레진 모형 근 관을 형성한 것이 아니고, 실험에서 사용한 $\mathrm{TF}$ 의 크기와 glide path 형성 방법 및 확대 정도 등이 다르기 때문인 것 으로 추정된다.

$\mathrm{TF}$ 제조사에서는 수동기구로 \#15까지 확대한 후 기 구가 근관 벽에 끼는 느낌이 적은 경우에는 ML-1 크기 의 파일을 사용할 것을 권장하고 있는데, ${ }^{11}$ 이번 실험과 정에서 Pathfile \#019까지 확대 시에는 근관을 충분히 확 대한 상태이기 때문에 ML-1 크기의 기구를 사용하는 것 이 적절한 것으로 생각된다. 이번 연구에서는 발거된 자 연 치아 대신 레진 모형 근관을 사용했는데, 레진 모형 근 관의 경우 근관의 만곡의 각도 및 위치 등을 3차원적으로 표준화할 수 있다는 장점이 있지만, 자연치에 비해 경도 가 적다는 단점도 있다. ${ }^{15}$ 그러나, 이번 연구에서처럼 기구 의 내구성을 확인하여야 하는 실험에 실제 치아를 사용하 면 석회화 정도 및 만곡도의 표준화가 어려워 실험 결과에 영향을 줄 가능성이 있는 변수가 많아지게 된다. ${ }^{13}$ 따라서 이번 연구에서는 발거된 치아 대신 모든 시편이 일정한 경도를 가지는 레진 모형 근관을 이용했으며, 실험 조건 을 실험조건을 표준화하기 위하여 모든 근관에 동일하게 Pathfile을 이용한 glide path 형성 및 ProTaper Universal SX file을 이용한 coronal preflaring을 시행하였다.

Adaptive movement로 사용 시 기구의 수명이 증가한 반면, 근관장까지 근관을 형성하는데 소요된 작업시간이 유의하게 증가했는데 기구에 부하가 가해질 시에 의도적 으로 기구가 반대 방향으로 회전하는 동안에는 근관을 확대하지 않았기 때문에 전체 근관을 형성하는 데 소요 된 시간이 증가한 것으로 해석된다. 이는, TF-adaptive와 $\mathrm{TF}$ continuous rotation movement 동작에 따른 작업시 간의 유의한 차이가 없었던 이전의 연구와는 다른 결과 이다. ${ }^{16}$ 이전의 연구에서는 자연치아를 이용하여 작업장 을 통일하지 않고, 근관의 만곡도만을 표준화하여 실험 
한 반면, 이번 실험은 작업장과 만곡도가 일정한 모형 근 관을 사용했기 때문에 좀 더 표준화된 실험 환경이라고 볼 수 있다.

Adaptive movement로 사용 시에도 날풀림이 발생하 는 위치는 TFA군에서 $4.19 \mathrm{~mm}$, TFC군에서 $3.41 \mathrm{~mm}$ 로 두 군 사이에 유의한 차이가 발생하지 않아 기구의 변형 에 취약한 위치를 보완하지는 못한 것으로 생각된다. 이 위치는 임상적으로, 주로 치근단 $1 / 3$ 이 시작되는 위치로, 이 위치에서 근관의 심한 협착이나 만곡이 존재하는 경 우에 임상가는 $\mathrm{TF}$ 를 사용시에는 주의해서 사용해야 할 것으로 사료된다. ${ }^{13}$ 본 실험에서 기구의 날풀림이 발생한 위치는 $\mathrm{TFC}$ 군에서 기구 첨단으로부터 평균 $3.41 \mathrm{~mm}$ 떨어 진 위치였으며, TF의 파절 위치에 대한 $\mathrm{Kim}$ 등 $^{3}$ 의 연구에 서는 평균 $5.94 \mathrm{~mm}$ 에서 $\mathrm{TF}$ 가 파절되었다. 이전의 연구 에서는 $\mathrm{TF}$ 를 $40^{\circ}$ 의 만곡도를 가지는 강철 근관에 사용 하여 tortional fatigue 없이 cyclic fatigue 만을 받도록 설 계했으나, 본 연구에서 사용된 레진 모형 근관은 Schäfer 의 방법으로 16 측정된 $30^{\circ}$ 의 만곡도를 가지며, 기구가 근관 벽에서 비틀림 힘을 받는 상황으로 설계되었고, 만 곡이 시작되는 위치도 다르기 때문으로 사료된다.

이번 실험의 결과로만 볼 때 Adaptive movement 개발 외에 파일의 성질이나 특성이 개선되지는 않았기에, 기구 동작의 변경으로 내구성을 증가시켰지만 동시에 작업시 간은 오히려 증가하였고, 날풀림에 취약한 위치는 보완 하지 못하여, 기구의 장점을 해치지 않는 한도에서 추가 적인 보완이 필요할 것으로 사료된다.

\section{결론}

Twisted file 25/.08 size의 ML-1 파일을 adaptive movement와 continuous rotation movement 하에서 각 각 사용 시에는 adaptive movement로 사용 시 날풀림이 발생할 때까지 더 많은 근관을 확대할 수 있었으며, 작업 시간이 증가하였다. 따라서 첫 번째와 두 번째 귀무가설 은 기각되었다. 날풀림이 발생한 위치는 두 그룹 간에 유 의한 차이가 발견되지 않아 세 번째 귀무가설은 인정되 었다. 이번 연구의 한계점 내에서, adaptive movement는 TF의 내구성을 증가시켰다고 생각할 수 있으며, 향후 파 일의 movement 외에도 내구성을 증가시킬 수 있는 방법 에 대한 연구가 필요할 것이다.

\section{ORCID}

Sang-Ho Lee https://orcid.org/0000-0002-2282-118X

So-Ra Park https://orcid.org/0000-0002-7381-3278

Kyung-Mo Cho https://orcid.org/0000-0003-3464-9425

Se-Hee Park https://orcid.org/0000-0002-4052-4082

Jin-Woo Kim https://orcid.org/0000-0002-0004-0710

\section{References}

1. Cheung GS, Liu CS. A retrospective study of endodontic treatment outcome between nickel-titanium rotary and stainless steel hand filing techniques. J Endod 2009;35:938-43.

2. Larsen CM, Watanabe I, Glickman GN, He J. Cyclic fatigue analysis of a new generation of nickel titanium rotary instruments. J Endod 2009;35:4013.

3. Kim HC, Yum J, Hur B, Cheung GS. Cyclic fatigue and fracture characteristics of ground and twisted nickel-titanium rotary files. J Endod 2010;36:14752.

4. Pérez-Higueras JJ, Arias A, de la Macorra JC. Cyclic fatigue resistance of $\mathrm{K} 3, \mathrm{~K} 3 \mathrm{XF}$, and twisted file nickel-titanium files under continuous rotation or reciprocating motion. J Endod 2013;39:1585-8.

5. Bouska J, Justman B, Williamson A, DeLong C, Qian F. Resistance to cyclic fatigue failure of a new endodontic rotary file. J Endod 2012;38:667-9.

6. Higuera O, Plotino G, Tocci L, Carrillo G, Gambarini $G$, Jaramillo DE. Cyclic fatigue resistance of 3 different nickel-titanium reciprocating instruments in artificial canals. J Endod 2015;41:913-5.

7. Özyürek T. Cyclic Fatigue Resistance of Reciproc, WaveOne, and WaveOne Gold Nickel-Titanium Instruments. J Endod 2016;42:1536-9.

8. Pedullà E, Lo Savio F, Boninelli S, Plotino G, Grande NM, La Rosa G, Rapisarda E. Torsional and Cyclic Fatigue Resistance of a New NickelTitanium Instrument Manufactured by Electrical Discharge Machining. J Endod 2016;42:156-9.

9. Gambarini G, Piasecki L, Di Nardo D, Miccoli G, Di Giorgio G, Carneiro E, Al-Sudani D, Testarelli L. Incidence of Deformation and Fracture of Twisted 
File Adaptive Instruments after Repeated Clinical Use. J Oral Maxillofac Res 2016;7:e5.

10. Gambarini G, Plotino G, Piasecki L, Al-Sudani D, Testarelli L, Sannino G. Deformations and cyclic fatigue resistance of nickel-titanium instruments inside a sequence. Ann Stomatol (Roma) 2015;6:69.

11. Gambarini G. TF ${ }^{\mathrm{TM}}$ Adaptive: a novel approach to nickel-titanium instrumentation. X Endodontic Practice 2014;7:e2.

12. Reddy PJ, Kumar VS, Aravind K, Kumar HT, Vishal M B, Vizaikumar VN, Das R, Vamsilatha K. Canal Shaping with One Shape File and Twisted Files: A Comparative Study. J Clin Diagn Res 2014; 8:1-3.

13. Schäfer E, Diez C, Hoppe W, Tepel J. Roentgeno- graphic investigation of frequency and degree of canal curvatures in human permanent teeth. J Endod 2002;28:211-6.

14. Braga LC, Magalhães RR, Nakagawa RK, Puente CG, Buono VT, Bahia MG. Physical and mechanical properties of twisted or ground nickel-titanium instruments. Int Endod J 2013;46:458-65.

15. Shen Y, Cheun GSP. Methods and models to study nickel-titanium instruments. Endodontic Topics 2013;29:18-41.

16. Gambarini G, Giansiracusa Rubini A, Sannino G, Di Giorgio G, Piasecki L, Al-Sudani D, Plotino G, Testarelli L. Cutting efficiency of nickel-titanium rotary and reciprocating instruments after prolonged use. Odontology 2016;104:77-81. 


\section{Adaptive movement가 twisted file의 내구성과 작업 시간에 미치는 영향}

\section{이상호, 박소라, 조경모, 박세희, 김진우*}

강릉원주대학교 치과대학 치과보존학교실

목적: Wire를 꼬아서 제조한 twisted file (TF)이 개발된 이래, 최근에는 기존 twisted file의 내구성 및 절삭 효과를 증진시 키기 위하여 구동방식의 변형을 준 TF-adaptive movement가 소개되었다. 본 연구의 목적은 TF-adaptive movement가 twisted file의 내구성에 미치는 영향을 조사하는 것이다.

연구 재료 및 방법: J자 모양의 근관 형태를 가지는 레진 모형 근관에 twisted file을 이용하여 근관 형성 시 adaptive movement (TFA군)와 continuous rotation movement (TFC군)의 두 가지 구동 방식 하에서 파일의 내구성을 비교하 고, 각각의 모형 근관을 형성하는데 소요된 시간을 측정하였다. TF 파일을 사용할 때마다 치과용 현미경으로 TF의 날풀 림(unwind) 또는 변형 및 파절 여부를 관찰하여 그때까지 TF로 형성한 모형 근관의 수를 기록하고, 사진을 촬영하였다. 또한 twisted file의 첨단(D0)에서 날풀림이 발생한 지점까지의 직선 거리를 측정했다. 실험 결과는 0.05 의 유의수준에서 Mann-Whitney U test로 분석했다.

결과: 파일의 파절은 두 실험군 모두에서 발생하지 않았으며, TFC군은 TFA군에 비하여 날풀림이 발생하기 전까지 형 성한 모형 근관의 수가 통계적으로 유의하게 적었으며, 모형 근관을 작업장까지 성형, 확대하는데 걸린 시간은 TFA군이 TFC군에 비해 유의하게 길었다. 날풀림이 발생한 지점의 위치는 TFC군과 TFA군 사이에 유의한 차이가 발견되지 않았다. 결론: Twisted file을 adaptive movement mode로 사용하여 근관을 형성하면 날풀림이 발생하기 전까지 확대할 수 있 는 근관의 수가 증가했으나, 작업장까지 근관을 형성하는데 필요한 시간이 유의하게 증가했다. Adaptive movement와 continuous rotary movement 간에 기구의 날풀림이 발생하는 위치에는 유의한 차이가 발견되지 않았다.

(구강회복응용과학지 2019;35(1):20-6)

주요어: NiTi; twisted file; adaptive movement; 날풀림 실험

*교신저자: 김진우

(25457) 강원도 강릉시 죽헌길 7 강릉원주대학교 치과대학 치과보존학교실

Tel: 033-640-3189 | Fax: 033-640-3103 | E-mail: mendo7@gwnu.ac. kr

접수일: 2018년 11월 12일 | 수정일: 2019년 2월 25일 | 채택일: 2019년 3월 3일 